\title{
MARKET EFFICIENCY AND THE RETURNS TO TECHNICAL ANALYSIS
}

\section{Hendrik Bessembinder and Kalok Chan}

\author{
Department of Finance \\ College of Business \\ Arizona State University \\ Tempe AZ 85287-3906 \\ USA
}

December 1997

* Some results in this paper were included in our earlier working paper titled "Do the Profits from Technical Trading Rules Reflect Inefficiencies?" We thank William Brock, Peter Chung, Wayne Ferson, Avi Kamara, Ken Kroner, Mike Lemmon, Grant McQueen, Ed Rice, Paul Seguin, Rene Stulz, Doug Emery, two anonymous referees, and seminar participants at the University of Washington, the University of British Columbia, Southern Methodist University, and the Arizona Finance Symposium for insightful comments. Bessembinder acknowledges funding from the Dean's Council of 100 at Arizona State University. 


\title{
MARKET EFFICIENCY AND THE RETURNS TO TECHNICAL ANALYSIS
}

\begin{abstract}
We further investigate and provide interpretation for the intriguing Brock, Lakonishok, and LeBaron (1992) finding that simple forms of technical analysis contain significant forecast power for U.S. equity index returns. We document that the forecast ability is partially, but not solely, attributable to return measurement errors arising from nonsynchronous trading. We argue that the evidence of technical forecast power need not be inconsistent with market efficiency. "Breakeven" one-way trading costs are computed to be $0.39 \%$ for the full sample and $0.22 \%$ since 1975 , which are small compared to recent estimates of actual trading costs. Further, we test but fail to reject a key restriction that most equilibrium models place on return forecast ability: that the technical rules should not reliably identify periods of negative market risk premia.
\end{abstract}




\section{MARKET EFFICIENCY AND THE RETURNS TO TECHNICAL ANALYSIS}

Most empirical studies of technical analysis, including Fama and Blume (1966) and Jensen and Benington (1970), conclude that technical analysis is not useful for improving returns. In contrast, a more recent study by Brock, Lakonishok, and LeBaron (1992) demonstrates that a relatively simple set of technical trading rules possess significant forecast power for changes in the Dow Jones Industrial Average (DJIA) over a long sample period. ${ }^{1}$ Sharpe, Alexander, and Bailey (1995, p. 850) summarize the response of some observers to the recent evidence, stating that "the apparent success of these (technical) strategies offers a challenge to those who contend that the U.S. stock market is highly efficient." In this paper, we present additional empirical analysis of the technical rules examined by Brock et. al. Our objective is to assess the economic significance of their findings, focusing in particular on whether their findings constitute evidence of market inefficiencies.

If technical rules possess significant return forecast power, then in the absence of transaction costs or return measurement errors, traders can use the rules to improve returns relative to a "buy-andhold" strategy. However, since technical trading strategies require frequent transactions, return forecastability may not imply increased returns once transaction costs are considered. We determine the level of transaction costs that would just eliminate the ex post difference between cumulative returns to traders using the technical rules versus those who buy and hold the Dow securities. We find that breakeven one-way trading costs are quite small, averaging $0.39 \%$ for the full 1926 to 1991 sample. We also examine four sub-periods: 1926-1943, 1944-1959, 1960-1975, and 1976-1991, and find that average breakeven costs decline over time, from $0.54 \%$ in the first sub-period to $0.22 \%$ in the last. These estimated break-even costs are similar to or smaller than recent estimates of actual trading costs,

\footnotetext{
1 Bessembinder and Chan (1995) report that the same rules are useful for forecasting index returns for a group of Asian stock markets, while Sweeney (1986) documents the success of similar technical rules for forecasting changes in currency exchange rates.
} 
implying that traders likely could not have used this set of technical rules to improve returns net of trading costs during the sample period.

Brock et. al. document that the average change in the DJIA on days that the technical rules emit sell signals is negative. They conclude (p. 1757) that "this negative conditional return over a large fraction of trading days is an intriguing result because predictably negative returns are inconsistent with existing equilibrium models." We further evaluate this issue. While equilibrium asset pricing models allow for return forecast ability stemming from variation in conditional expected returns, most models restrict the conditional risk premium on the market portfolio to be strictly nonnegative. If the DJIA is viewed as a market proxy, then the equilibrium models imply that technical analysis should not reliably predict periods when DJIA returns are less than risk free interest rates. We use a bootstrap methodology to test this implication, and find that while the average ex post Dow Jones risk premium during technical sell signals is negative, the point estimates are economically small (averaging $-0.57 \%$ per year) and statistically indistinguishable from zero. Thus, we find insufficient evidence to reject the equilibrium implication that the market risk premium is nonnegative.

Finally, we evaluate the possibility that the return forecastability documented by Brock et al. could simply reflect measurement errors in portfolio returns arising due to nonsynchronous trading. We find that excluding the first trading day following initiation of a technical buy or sell signal, (which should provide a complete correction for the effects of nonsynchronous trading for the heavily-traded Dow securities) reduces but does not eliminate the evidence of technical forecast power. Hence we conclude that the technical forecast power is not solely attributable to return measurement errors.

The technical forecast power identified by Brock et al. does not, by classical statistical criteria, justify a rejection of implications of modern asset pricing theories. Further, the degree of forecast ability is not large when measured relative to estimates of actual trading costs. We conclude that there is little reason to view the evidence as indicative of market inefficiencies. Still, we view the evidence 
that the simple technical rules do contain forecast power to be intriguing. Identification of the reasons that DJIA returns can be predicted to a statistically significant degree by simple technical analysis remains an interesting and unresolved issue.

\section{The technical rules and measurement of returns}

\section{A. Description of the Rules.}

Brock et. al. emphasize the danger of obtaining spurious empirical results if trading rules are both discovered and tested in the same data set. They note that there is no complete remedy for "data snooping" biases, but attempt to mitigate the problem by using a long data series and by reporting results for all rules evaluated. To avoid compounding the dangers of data snooping biases, we evaluate precisely the same set of twenty six technical rules as Brock et. al. These include ten Variable Length Moving Average (VMA) rules, ten Fixed Length Moving Average (FMA) rules, and six Trading Range Break (TRB) rules.

VMA rules involve comparison of a short-term moving average of prices to a long-term moving average. Buy (sell) signals are emitted when the short-term average exceeds (is less than) the long-term average by at least a pre-specified percentage band. A [S-L] 1200 rule, for example, emits buy (sell) signals when the [S-day moving average of price] eurrent price exceeds (is less than) the-200-day [Lday] moving average of prices. Other variations [The VMA rules] evaluated by Brock et al. include 1$50,1-150,[1-200] 5-$,150 , and 2-200. Each rule is evaluated with bands of 0 and $1 \%$, making for ten moving average combinations in total.

The FMA rules evaluated by Brock, et al. generate buy (sell) signals when the short-term moving average cuts the long term moving average from below (above). The FMA rules differ from the VMA rules only in that the buy or sell signal is assumed to be issued for a fixed number of (Brock et al. use 10) days after it is initiated, while VMA signals continue to be issued until the next crossing 
of the short and long averages.

TRB rules emit buy (sell) signals when the current price moves above the recent maximum (below the recent minimum). Brock et al. evaluate TRB rules where the recent maximum or minimum are based on the past 50,150, and 200 days. Each of these is evaluated with and without a one percent band, making for six TRB rules in total.

Brock et al. provide some more detailed description and historical perspective on these rules, which we do not repeat. Two points should be noted, however. First, these rules are positive reinforcement or momentum strategies. Traders potentially profit from use of these rules if prices continue to move in the same direction as the price change that initiated a signal. Second, the proportion of days that technical traders hold positions varies across strategies: under the VMA rules positions taken in response to buy and sell signals are held until the signal ceases to be generated. Under the FMA and TRB rules positions taken in response to buy and sell signals are held for a fixed ten-day horizon.

\section{B. Measuring Returns}

The results reported by Brock et al. are based on percentage changes in the DJIA, data on which was available for a long time horizon. However, some limitations of the Dow Jones data potentially affect the interpretation of their evidence. First, changes in the industrial average [stock index] understate actual returns due to the omission of dividends. We do not expect this omission to have much effect on measures of differences between mean returns during technical buy signals and mean returns during technical sell signals, or on tests of whether the technical rules possess forecast power. However, the omission of dividends will introduce bias to tests of whether mean returns during periods of technical sell signals differ significantly from zero (or any other specific benchmark). Our estimate (described below) of the omitted dividend yield is $0.016 \%$ per day (approximately $4.5 \%$ per year), which is nontrivial relative to the average sell day returns reported by Brock et. al., which are - 
$0.025 \%$ for the VMA rules, $-0.040 \%$ for the FMA rules, and $-0.024 \%$ for the TRB rules.

To our knowledge, data on daily dividend yields for the stocks that make up the Dow-Jones average is not available prior to 1962. [Hank, the Dow Jones dividend yield that we obtain starts from 1978. The dividend yield that we retrieve from CRSP tape that starts from 1962 is not for DJIA]. We estimate dividend yields [construct dividend yield proxy] for the DJIA based on two sources. The first is the data set described by Schwert (1990), which includes daily returns with and without dividends for portfolios of U.S. equities from 1885 to 1962. The second is daily returns to the CRSP value weighted portfolio, with and without dividends, over the interval July 1962 to December 1991 . We estimate daily dividend yields by applying the algorithm provided by Fama and French (1988) to the combined Schwert-CRSP equity return series with and without dividends. Finally, we estimate DJIA returns as the sum of the percentage change in the DJIA (obtained from Pierce (1991) and from Data Resources Inc.) and the estimated dividend yield. We note that to the extent that the relatively mature Dow securities pay higher dividend yields than the estimates obtained from the broader equity indices we employ, estimated DJIA returns are still understated and the tests may still contain a slight bias in favor of finding negative risk premia. In section III.D below we report on some sensitivity tests regarding measurement of dividend yields.

A second concern regarding the use of the DJIA index to measure returns is that the index is constructed [in a price-weighted fashion] as a complex average of the component share prices. A trading strategy seeking to create returns that mimic changes in the DJIA would require [a buy-and-hold strategy which is restricted to an equal number of shares of DJIA stocks at the beginning, and whenever cash and stock dividends are paid, rebalance the portfolios so that the portfolio weights are in proportion to the share price of each stock.] frequent trades to reestablish the correct weights. We do not attempt to formally correct for this eomplexity [frequent adjustment]. However, we do assess in Section III.D below whether the rules contain similar forecast power for the CRSP value-weighted 
index, returns on which could be replicated without frequent adjustments.

We also require interest rate data if we are to test the market efficiency implication that the market risk premium is nonnegative. We obtain yields on one month Treasury bills from 1926 to 1991 from the Center for Research in Security Prices (CRSP) database, and compute ex post risk premia as the return on the DJIA less the beginning-of-month Treasury Bill rate. Our analysis is limited to the 1926 to 1991 interval by the unavailability of earlier interest rate data. ${ }^{2}$

\section{Methodology}

\section{A. General Framework}

${ }^{2}$ It should be noted that the technical forecast power was generally stronger prior to 1925 . As a consequence, we report buy-sell differentials that are somewhat smaller than those reported by Brock et. al, whose sample commenced in 1897. 
We evaluate trading costs and conduct tests of a key implication of modern asset pricing models using the following framework. Let $R_{t}$ denote the day $t$ return on the DJIA, $i_{t}$ denote the day $t$ risk free interest rate, and $r_{t}=R_{t}-i_{t}$ denote the DJIA return in excess of the interest rate. Let $\pi_{\text {it }}$ denote the additional (pre-trading cost) day t return earned by a trader relying on technical rule i as compared to that earned by an investor who passively holds the DJIA. We consider the results of a "double-or-out" strategy, in which a trader simply holds the Dow Jones portfolio in the absence of a trading signal, liquidates the portfolio in favor of Treasury bills in response to sell signals, and borrows (at the T-bill rate) to double the equity position in response to buy signals. ${ }^{3}$ During buy signals the trader earns a return of $2 R_{t}-i_{t}$, which exceeds the buy and hold return by $r_{t}$, so $\pi_{\mathrm{it}}=\mathrm{r}_{\mathrm{t}}$. During sell signals the trader earns a return of $\mathrm{i}_{\mathrm{t}}$, which exceeds the return from passively holding the Dow by $-\mathrm{r}_{\mathrm{t}}$, implying that $\pi_{\mathrm{it}}=$ $-r_{t}$ When rule i does not generate a signal the trader holds the Dow securities to earn $R_{t}$, so $\pi_{\text {it }}=0$.

Let $\pi_{\mathrm{i}}^{\mathrm{B}}$ denote the sum of $\pi_{\mathrm{it}}$ across the subset of sample days for which rule $\mathrm{i}$ emits buy signals, $\pi_{\mathrm{i}}^{\mathrm{S}}$ denote the sum of $\pi_{\mathrm{it}}$ across the subset of sample days during which rule i emits sell signals, and let $\pi_{\mathrm{i}}=\pi_{\mathrm{i}}^{\mathrm{B}}+\pi_{\mathrm{i}}^{\mathrm{S}}$. The quantity $\pi_{\mathrm{i}}$ measures the improvement (prior to deducting transaction costs) in the trader's total return (final wealth per dollar initially invested) over the sample period due to using technical rule i instead of a buy-and-hold strategy.

Whether technical rule i has power to improve pre trading cost returns can be evaluated by testing whether $\pi_{\mathrm{i}}$ differs significantly from zero. Whether the technical rules identify periods when risk premia are reliably less that zero can be evaluated by testing the hypothesis that $\pi_{\mathrm{i}}^{\mathrm{S}}$ equals zero

\footnotetext{
${ }^{3}$ Though we refer to a "double or out" strategy, the computed breakeven costs actual apply to any symmetric strategy in which the investor responds to buy signals by increasing the equity position by $\mathrm{X} \%$ and responds to sell signals by decreasing the equity position by $\mathrm{X} \%$. The double or out strategy is similar in spirit to the simple comparisons provided by Brock, et al.on page 1742 of their article. Note, though, that they simply use the percent change in the index, while we argue that the appropriate measure is $\pi_{\text {it }}$ defined above, which includes dividend payments but is stated in excess of interest rates. In addition to symmetric strategies such as "double-orout", a wide variety of asymmetric strategies where reactions to buy and sell signals differ could be evaluated. However, in the absence of compelling reasons to choose specific strategies, the danger of data snooping biases is potentially increased by a wider search.
} 
against that alternative that $\pi_{\mathrm{i}}^{\mathrm{S}}$ is positive. A reliably positive outcome on $\pi_{\mathrm{i}}^{\mathrm{S}}$ would indicate improvements in returns attributable to the successful identification of periods of negative risk premia.

\section{B. Breakeven Costs}

Let $\mathrm{C}$ denote the percentage cost of moving from an equity index into risk-free securities or vice versa. Each new trading signal results in trades of two times portfolio value. For new signals that shift the position from "double" to "out" or vice versa the costs are immediate. New trading signals that arrive while the trader is holding a standard long position generate an immediate trading cost of $\mathrm{C} \%$, plus another $\mathrm{C} \%$ when the position is eventually reversed. Let $\mathrm{N}_{\mathrm{i}}$ denote the number of new positions taken in response to buy and sell signals emitted by rule i during the sample interval.

Accumulated trading costs exactly consume the additional return to using technical rule i instead of buyand-hold if $\pi_{\mathrm{i}}=2 \mathrm{~N}_{\mathrm{i}} \mathrm{C}$, so the breakeven one way trading cost for rule $\mathrm{i}$ is $\mathrm{C}_{\mathrm{i}}=\pi_{\mathrm{i}} / 2 \mathrm{Ni}_{\mathrm{i}}{ }^{4}$

\section{Aggregating Across Trading Rules}

\footnotetext{
${ }^{4}$ An alternate approach would be to compute the breakeven costs that equate the sum of the continuously compounded returns to following the technical rule with the sum of the continuously compounded buy-and-hold returns, which would ensure equal terminal wealth. At a practical level each approach yields nearly identical results. Aggregated across all twenty six trading rules, the breakeven cost that equates simple returns is $0.39 \%$, while the breakeven cost that equates continuously compounded returns is $0.40 \%$.
} 
We follow Brock et. al. in evaluating twenty six technical trading rules. Brock et. al. do not report any statistical tests that pertain to the full set of rules. Focusing on those rules that are ex post most (or least) successful would also amount to a form of data snooping bias. ${ }^{5}$ We wish to report empirical results and statistical tests that reflect the collective evidence obtained from all twenty six rules. This is complicated by the fact that results for the various rules, having all been obtained from the DJIA return series, are not statistically independent of each other. To obtain empirical evidence aggregated across these interdependent rules, we adopt a portfolio approach, and assess the profitability and statistical significance of portfolio returns. We consider four portfolios, one each devoted to the VMA rules, the FMA rules, and the TRB rules, and one allocated across all twenty six rules. In each case, we consider results for portfolios with an equal portion of capital initially allocated to each component technical rule. Since portfolio returns are comprised of individual trading rule returns, the sample distribution of portfolio returns reflects the lack of independence- [interdependence] across rules. 
Suppose that a trader allocates the fraction $1 / \mathrm{n}$ of her initial portfolio to each of $\mathrm{n}$ trading rules. Applied to only the fraction $1 / \mathrm{n}$ of the original capital, the contribution of rule $\mathrm{i}$ to increased total portfolio return is reduced proportionately to $\pi_{\mathrm{i}} / \mathrm{n}=\pi_{\mathrm{i}}^{\mathrm{B}} / \mathrm{n}+\pi_{\mathrm{i}} / \mathrm{n}^{\mathrm{S}}{ }^{6}$ Summing across the $\mathrm{n}$ rules, the improvement in total portfolio return (final wealth per dollar initially invested) from using the set of $n$ trading rules instead of a buy-and-hold strategy is $\pi \mathrm{P}=\pi \mathrm{P}^{\mathrm{B}}+\pi \mathrm{P}^{\mathrm{S}}$, where $\pi \mathrm{P}^{\mathrm{B}}$ is the average across the $\mathrm{n}$ rules of the $\pi_{\mathrm{i}}^{\mathrm{B}}$ and $\pi_{\mathrm{P}}^{\mathrm{S}}$ is the average across the $\mathrm{n}$ rules of the $\pi_{\mathrm{i}}^{\mathrm{S}}$. The hypothesis that the set of technical rules have no forecast power, or equivalently that the set of trading rules have not improved pre trading cost portfolio returns, can be assessed by testing whether $\pi_{\mathrm{P}}$ equals zero. The hypothesis that the group of technical rules collectively identify periods when the market risk premium is negative, or equivalently that trading on technical sell signals has improved returns, can be examined by testing whether $\pi \mathrm{P}^{\mathrm{S}}$ equals zero.

With only $1 / \mathrm{n}$ of initial capital applied to rule $\mathrm{i}$, each pair of trades due to rule i signals reduces portfolio returns by $2 \mathrm{C} / \mathrm{n}$ percent. Since rule i emits $\mathrm{N}_{\mathrm{i}}$ trade signals in total, rule i trades reduce portfolio returns by $2 \mathrm{NiC}_{\mathrm{i}}$ n percent. Summing across the $\mathrm{n}$ rules, trading costs reduce final portfolio returns by $2 \mathrm{~N}_{\mathrm{p}} \mathrm{C}$ percent, where $\mathrm{N}_{\mathrm{p}}$ is the average across the $\mathrm{n}$ rules of the number of trading signals emitted, $\mathrm{N}_{\mathrm{i}}$. The percentage trading cost that would just leave portfolio trading returns equal to buyand-hold returns is obtained by equating the improvement in pre-trading cost portfolio returns, $\pi_{\mathrm{P}}=\pi_{\mathrm{P}}^{\mathrm{B}}$ $+\pi_{\mathrm{P}} \mathrm{S}$, with total trading costs, $2 \mathrm{~N}_{\mathrm{p}} \mathrm{C}$, to obtain $\mathrm{CP}_{\mathrm{P}}=\pi_{\mathrm{P}} / 2 \mathrm{~N}_{\mathrm{P}}$. Note that the breakeven trading cost for the portfolio is obtained as the excess portfolio return (which is the average of individual rule excess returns) divided by average trading activity, rather than as the average of individual rule breakeven costs.

\section{Correcting for Nonsynchronous Trading}

\footnotetext{
${ }^{6}$ Note that, although the $\mathrm{n}$ positions are initially equal-weighed they do not remain so, and the final $\pi_{\mathrm{i}}$ vary depending on each rule's ex post success. Hence, no periodic portfolio balancing need be assumed.
} 
Scholes and Williams (1977)) show that the nonsynchronous trading of component securities induces spurious positive serial dependence in measured portfolio or index returns. Since the technical rules evaluated here rely on positive serial dependence, their apparent success may reflect return measurement errors. We evaluate this possibility by investigating the sensitivity of all results to implementation of a one day lag, in which technical trading returns are measured beginning with the closing index value one day after a technical signal is initiated. Omitting the first day return eliminates the bias in measured returns attributable to nonsynchronous trading if each security trades during the intervening day. This seems a reasonable assumption for the heavily traded Dow stocks.

\section{Empirical Results}

In Table 1 we report returns to technical trading, numbers of trades, breakeven costs, and outcomes of hypothesis tests for the 1926 to 1991 sample, for each individual technical rule and for the four portfolios described above. The columns labeled "Buy", "Sell", and "Buy-Sell" reflect the quantities $\pi_{\mathrm{i}}^{\mathrm{B}},-\pi_{\mathrm{i}}^{\mathrm{S}}$, and $\pi_{\mathrm{i}}^{\mathrm{B}}+\pi_{\mathrm{i}}^{\mathrm{S}}$ as defined above, except that each has been annualized by dividing by the number of years in the sample. We also report breakeven costs and bootstrap p-values on the hypotheses described in Section II. The computation of these p-values is detailed in the appendix.

In Table 2 we report results for each of four sub periods of approximately equal length, 1926 to 1943, 1944 to 1959,1960 to 1975 , and 1976 to 1991 , the last of which is chosen to represent the period of reduced transaction costs following commission deregulation in May 1975. To facilitate comparison we also report results for the 1939 to 1961 and 1962 to 1986 sub periods that were used by Brock, et. al. To economize on space, sub period results are reported for portfolios but not individual rules. Table 1 and Panel A of Table 2 reports results obtained when trading returns are measured beginning with the closing index value that initially generates a signal, while on Panel B of Table 2 we report portfolio results obtained when the one day lag is imposed to allow for the effects of nonsynchronous 
trading.

\section{A. Forecast Power of the Technical Rules}

The hypothesis that $\pi \mathrm{P}^{\mathrm{B}}+\pi \mathrm{P}^{\mathrm{S}}=0$, which states that the technical rules in aggregate have no predictive power for returns, is soundly rejected. For the full 1926 to 1991 sample, and aggregated across all twenty six rules, the differential in annual returns occurring during buy versus sell signals is 4.39\%. The bootstrap p-value on the hypothesis that $\pi \mathrm{P}^{\mathrm{B}}+\pi_{\mathrm{P}}^{\mathrm{S}}=0$ is .000 , which reflects that none of the 500 bootstrap simulations generated a buy-sell differential as large as that observed in the actual data. Imposition of a one day lag reduces the buy-sell return differential to $3.23 \%$ per year, but the pvalue increases to only .002 . This indicates that while the technical forecast power may be partially attributable to return measurement errors arising from nonsynchronous trading, significant forecast power derives from other sources as well.

We note, though, that the evidence of technical forecast power has weakened in recent years. For the 1976-1991 interval the annual buy-sell return differential aggregated across all twenty six rules is $2.51 \%$, with an associated bootstrap p-value of .252 in the absence of trading lags. The corresponding buy-sell differential is only $1.25 \%$ with a bootstrap p-value of .490 when a one day lag is imposed. $^{7}$ For the final sub period, the hypothesis that the technical rules as a group possess no forecast power cannot be rejected at conventional significance levels.

\section{B. Negative Market Risk Premia}

The hypothesis that $\pi_{\mathrm{P}}^{\mathrm{S}}=0$, which implies the absence of negative market risk premia during periods of technical sell signals, cannot be rejected. Aggregated across all rules, and in the absence of any trading lag, the p-value on this hypothesis is .360 . This p-value reflects that 180 of the 500 bootstrap simulations conducted under the null hypothesis that returns equal zero generated sell day

${ }^{7}$ This reduction in forecast power is not attributable to the large return outliers of October 1987. Rather, most of the rules correctly emitted sell signals prior to the large price drop of October 19. 
returns more negative than observed in the actual sample. Imposition of a one day trading lag to allow for nonsynchronous trading increases the $\mathrm{p}$-value on the hypothesis that $\pi_{\mathrm{P}} \mathrm{S}=0$ to .514 . These results reflect that the technical rules have little success in predicting negative risk premia: aggregated across all rules, point estimates of $\pi_{\mathrm{P}}^{\mathrm{S}}$ are only $-0.57 \%$ per year in the absence of trading lags or $-0.04 \%$ per year when the one day trading lag is imposed. These estimates are insufficiently distant from zero to support a rejection of the nonnegative risk premium implication of most equilibrium asset pricing models.

\section{Breakeven Trading Costs}

For the full sample, aggregation across all rules gives a buy-sell return differential of $4.39 \%$ per year, and ex post breakeven one-way transactions costs of $0.39 \% .^{8}$ Ex post profitability and breakeven costs vary across rules. As a group, the VMA rules provided the largest buy-sell return differential, $8.56 \%$ per year, allowing the highest breakeven costs, $0.57 \%$ per year. The FMA and TRB rules generated buy-sell differentials of only $1.90 \%$ and $1.59 \%$ per year, respectively, allowing breakeven costs of $0.25 \%$ and $0.14 \%$, respectively. ${ }^{9}$ However, in the absence of ex ante reasons to prefer some rules, we view the breakeven cost computed across all evaluated rules as providing the most appropriate benchmark. Imposition of a one day lag reduces breakeven costs aggregated across all

8 Comparisons of returns and breakeven trading costs are less meaningful if the overall riskiness of the returns obtained from the technical strategies differs substantially from the riskiness of buy and hold returns. In fact, the overall risk borne by a trader applying the double-or-out strategy for the set of technical rules evaluated here is quite similar to the risk of buy and hold returns. The standard deviation of the daily buy and hold returns for the full sample is $1.12 \%$. By comparison, standard deviations of daily returns for portfolios allocated to the 10 VMA rules, the 10 FMA rules, and the 6 TRB rules are $1.30 \%, 1.09 \%$, and $1.11 \%$, respectively. The standard deviation of daily returns for a trader using a portfolio allocated to all 26 technical rules is $1.08 \%$, slightly smaller than the risk of a buy and hold position.

${ }^{9}$ Note that the reported returns are those that accumulated during periods when buy and sell signals were in effect, and that they do not represent annualized returns. As such, they reflect the relative scarcity of FMA and TRB signals. On average the FMA rules generated 3.75 signals per year while the TRB rules generated 5.59 signals per year, each accompanied by a 10 day holding period. Thus no TRB or FMA signal is in effect during most of the 269 trading days per year. 
rules to $0.29 \%$ from $0.39 \%$.

Breakeven costs have declined over time. Aggregated across all rules the buy-sell differential for the 1926 to 1943 sub sample was $6.87 \%$ per year, which allowed breakeven costs of $0.54 \%$. The annual buy-sell differential has declined since, to $4.24 \%$ in the 1944 to 1959 interval, $3.62 \%$ in the 1960 to 1975 interval, and $2.51 \%$ in the most recent 1976 to 1991 period. As a consequence breakeven costs declined as well, to $0.22 \%$ for the most recent sub sample. With a one day lag imposed breakeven costs for the post 1976 sample are just $0.11 \%$.

If traders' actual costs are higher than these breakeven costs, then trading on the technical signals would have reduced returns during the sample period, and vice versa. Knez and Ready (1995) estimate the average effective bid-ask spread actually paid in a one way trade for Dow Jones securities to be between $0.11 \%$ and $0.13 \%$. Chan and Lakonishok (1993) estimate commissions costs for institutional traders transacting in the largest decile of NYSE securities to be $0.13 \%$. Combining these estimates of effective bid-ask spreads and commissions gives estimated one-way equity trading costs of $0.24 \%$ to $0.26 \%$ for institutional traders. Kroner (1995) reports that Wells Fargo Nikko Investment Advisors estimates its own one-way trading costs to be $0.25 \%$ plus market impact. Traders would also incur costs to buy and sell interest-bearing securities. We note that despite the exclusion of the costs of trading treasuries, estimated trading costs are uniformly higher than the ex post breakeven costs $(0.22 \%$ without a lag or $0.11 \%$ with a one-day lag) for the most recent sub period.

These cost estimates pertain to very recent history. Trading costs were likely greater in earlier years, particularly before commissions were deregulated in May 1975. Stoll and Whaley (1983) use published commission schedules to estimate trading costs during the 1960 to 1975 period. They report commissions of $1.01 \%$ and average quoted bid-ask spreads of $0.69 \%$ for the largest decile of NYSE securities, for an estimated one-way transaction cost of $1.35 \%$ (the commission plus half the bid-ask spread). This figure may overstate actual trading costs during that interval, since it does not 
accommodate the possibility of trading within the quotes or allow for non-price inducements that tend to arise when prices are regulated. We note though, that this trading cost estimate is much larger than the ex post breakeven costs for the same period, which are $0.36 \%$ without any trading lag, or $0.23 \%$ if a one day lag is imposed. We are not aware of specific estimates of trading costs prior to 1960. Nor are we aware of any reason to believe that trading costs were lower in earlier decades. We conclude that it is unlikely that traders could have used the set of technical rules evaluated by Brock et. al. to improve returns net of trading costs.

\section{Sensitivity Tests}

In section I above we make note of some problems inherent in the use of changes in the DJIA to measure returns. One is the absence of dividends. While we attempt to correct for this omission by using dividend series obtained from broader equity indices, our correction is imperfect in that it does not directly capture the dividends of the Dow securities. Another problem is that obtaining portfolio returns that match the DJIA requires periodic trades to re-balance the portfolio. A third consideration is that the "no negative risk premia" implication of modern asset pricing models applies to the market portfolio, for which the DJIA is an imperfect proxy. In particular, the omission of returns on smaller capitalization securities could bias the tests towards finding smaller or negative premia. In this section we report on a set of sensitivity tests that partially address these concerns.

We were able to obtain the actual dividend yield for the Dow 30 securities for the interval 1978 to 1991 . On Table 3 we report results of implementing the 26 technical rules for this period when returns include the actual Dow dividends and when the returns include dividends imputed from a broader portfolio, the CRSP value weighted index. (In each case the capital gain component of returns is based on changes in the DJIA). The results indicate some moderate sensitivity to the method of dividend measurement. The buy-sell differential averaged across all rules is $3.12 \%$ per year with Dow dividends compared to $2.20 \%$ per year with CRSP dividends. Our main concern with dividend 
omission was the downward bias in mean returns. Here, we observe that average returns are greater (during both buy and sell signals) with Dow dividends than with CRSP dividends. This is consistent with the reasoning that the use of dividend yields from broader equity indices provides only a partial adjustment for the downward bias in returns due to dividend omission, and further weakens the apparent evidence of negative risk premia after technical sell signals.

On Table 4 we report empirical results obtained when the 26 technical trading rules are implemented using data from 1962 to 1991 on the CRSP value-weighted index. Using CRSP data provides insights in two ways. First, the dividend yield is measured accurately. To assess sensitivity to the exclusion of dividends, we report results where returns are measured inclusive and exclusive of dividend yields. Second, the CRSP index includes a broader set of firms than the DJIA and is therefore likely to comprise a better proxy for the market portfolio.

We find that the technical rules are also successful in forecasting CRSP returns. The buy-sell differential is $3.92 \%$ per year inclusive of dividends and $3.56 \%$ per year exclusive of dividends, with a bootstrap p-value of 0.000 in each case. Further, the point estimate of average returns during sell signals is negative in each case. However, the estimates are economically small, averaging $-0.77 \%$ per year when dividends are included and $-1.50 \%$ per year when dividends are excluded, and the bootstrap p-values are 0.208 when excluding dividends and 0.310 when including dividends. These indicate a substantial likelihood that the point negative estimates could reflect random outcomes. On balance, we view these sensitivity tests as supporting our main conclusions that the technical rules have statistically significant forecast power, but that the differentials in buy and sell returns are small in economic terms and fail to reject the implications of market efficiency.

\section{Conclusions}

Brock, et. al. (1992) demonstrate that a set of relatively simple technical trading rules possess 
statistically significant forecast power for changes in the Dow Jones Industrial Average over a long sample period. We extend their analysis to ascertain whether this evidence can be reconciled with market efficiency.

We confirm the basic Brock, et. al. results, and we document that the forecast power is not solely attributable to return measurement errors arising from nonsynchronous trading. However, we argue that this evidence can coexist with the notion of market efficiency. "Breakeven" one-way trading costs, which would just eliminate increases in portfolio returns from using the technical rules, are $0.39 \%$ for the full sample and $0.22 \%$ since 1975 (0.11\%after allowing for return measurement errors), which are small compared to recent estimates of actual trading costs. Further, we test and fail to reject a key restriction that most equilibrium models place on return forecast ability: that the technical rules should not reliably identify periods of negative market risk premia. We conclude that there is little reason to view the evidence presented by Brock et. al. as indicative of market inefficiencies. We note also the similarities between this analysis and studies of gambling markets that document the apparent profitability of some betting strategies prior to deducting trading costs, but the absence of profits after allowing for costs (see, e.g., Gray and Gray (1997) and Golec and Tamarkin (1991)).

We argue that the evidence of technical forecast power need not be inconsistent with market efficiency. However, we do not dismiss the evidence as unimportant or uninteresting. Kandel and Stambaugh (1996) note that evidence of stock return predictability that seems weak when evaluated by classical statistical criteria may nevertheless be economically important in the sense that a rational Bayesian investor would substantially alter portfolio holdings in response to the evidence. Hence, the negative point estimates of the market risk premium could in principle be economically important even if statistically insignificant and consistent with market efficiency. Further, determination of the source of the technical forecast power documented by Brock et. al. remains an interesting and unresolved issue. 


\section{Appendix: Computation of the Bootstrap P-values.}

We use bootstrap methodologies to assess the statistical significance of our various point estimates. We test the hypotheses that $\pi_{\mathrm{i}}=\pi_{\mathrm{i}}^{\mathrm{B}}+\pi_{\mathrm{i}}^{\mathrm{S}}=0$ and that $\pi \mathrm{P}=\pi \mathrm{P}^{\mathrm{B}}+\pi \mathrm{P}^{\mathrm{S}}=0$, which represent the null hypotheses that rule i individually and a set of rules in aggregate have no power to improve the technical traders' pre-trading cost returns, using a procedure very similar to Brock et. al. The set of actual DJIA returns is scrambled, which eliminates any serial dependence in the returns so that the bootstrap distribution conforms to the null of no forecast power, and a simulated DJIA is created by linking the scrambled returns. Each of the twenty six technical rules is fit to the simulated index, and returns to each rule and to the portfolios are recorded. This procedure is repeated 500 times. The proportion of simulation outcomes where the computed $\pi_{\mathrm{i}}$ and $\pi_{\mathrm{P}}$ exceed the point estimates from the actual sample comprise bootstrap p-values for the hypotheses that $\pi_{\mathrm{i}}$ and $\pi_{\mathrm{P}}$ equal zero.

The nonnegative risk premium hypothesis is evaluated by testing whether $\pi_{\mathrm{i}}^{\mathrm{S}}$ and $\pi_{\mathrm{P}}^{\mathrm{S}}$ equal zero. Efron and Tibshirani (1993, chapter 16) stress that hypothesis testing with the bootstrap procedure requires that the bootstrap distribution conforms to the null hypothesis. Since the mean of scrambled DJIA returns is nonzero, a bootstrap distribution created from actual DJIA returns is inappropriate for testing the null hypothesis that mean returns during sell signals equal zero. We follow Efron and Tibshirani and transform the empirical distribution so that it conforms to the null hypothesis.

We create a transformed distribution with a zero mean for each technical rule, by deducting from each individual sell day return the sample mean return observed on that rule's sell days. The transformed sell day returns are scrambled, and for each rule a sample equal in size to that obtained from the actual data is drawn at random with replacement. The sum of these returns is then recorded

for each rule. The procedure is repeated 500 times. The bootstrap p-value for the hypothesis that $\pi_{\mathrm{i}}^{\mathrm{S}}=$ 0 is given by the proportion of the 500 simulated rule i sell day return sums that are smaller than the sum of rule i sell day returns observed in the actual data. 
Obtaining a bootstrap p-value on the hypothesis that $\pi \mathrm{P}^{\mathrm{S}}$, the accumulated portfolio return attributable to trading on technical sell signals, equals zero requires that we use a procedure that maintains the dependencies across rules that exist in the actual data. To do so, returns are drawn from each of the transformed distributions by date. Let $\mathrm{R}_{\mathrm{it}}$ denote the transformed date $\mathrm{t}$ return for rule $\mathrm{i}$, and let $\mathrm{R}_{\mathrm{Pt}}$ denote the mean across rules of $\mathrm{R}_{\mathrm{it}}$, with the convention that $\mathrm{R}_{\mathrm{it}}$ equals zero if day $\mathrm{t}$ is not a sell day for rule i. We draw at random, with replacement, a sample of size $\mathrm{T}$ from the set of $\mathrm{T}$ sample dates. For each date, we compute Rpt, and sum these over the $\mathrm{T}$ observations. This procedure is repeated 500 times. The proportion of these 500 simulated sums that are smaller than the level of $\pi \mathrm{P}^{\mathrm{S}}$ observed in the actual sample comprises the bootstrap p-value for the hypothesis that $\pi_{\mathrm{P}}^{\mathrm{S}}$ equals zero. 


\section{REFERENCES}

Bessembinder, H. and K. Chan, 1995, "The profitability of technical trading rules in the Asian stock markets", Pacific-Basin Finance Journal, 3, 257-284.

Brock, W., J. Lakonishok, and B. LeBaron, 1992, "Simple technical trading rules and the stochastic properties of stock returns", Journal of Finance, 47, 1731-1764.

Chan, L., and J. Lakonishok, 1993, "Institutional trades and intraday stock price behavior", Journal of Financial Economics, 33, 173-199.

Efron, B., and R. Tibshirani, 1993, An Introduction to the Bootstrap, Chapman and Hall, New York.

Fama, E., and K. French, 1988 "Dividend yields and expected stock returns" Journal of Financial Economics, 22, 3-26.

Fama, E., and M. Blume, 1966, "Filter rules and stock market trading profits", Journal of Business, 39, 226-241.

Golec, J. and M. Tamarkin, 1991, "The degree of inefficiency in the football betting market" Journal of Financial Economics, 30, 311-323.

Gray, P. and S. Gray, 1997, “Testing Market Efficiency: Evidence from the NFL Sports Betting Market", Journal of Finance, 52, 1725-1736.

Jensen, M. and G. Benington, 1970, "Random walks and technical theories, Some additional evidence", Journal of Finance 25, 469-482.

Kandel, S. and R. Stambaugh, 1996, "On the predictability of stock returns: an asset allocation perspective", Journal of Finance, 51, 385-424.

Knez, P. and M. Ready, 1996, "Estimating the profits from trading strategies", Review of Financial Studies, 9, 1121-1164.

Kroner, K. 1995, "Comments on 'Do the profits from technical trading rules reflect inefficiencies?' ", unpublished mimeo, Wells Fargo Nikko Investment Advisors Advanced Strategy Group, San Francisco.

Pierce, P., ed., 1991, The Dow Jones Averages: 1885-1990 (Business One Irwin, Home-wood, Ill.).

Scholes, M. and J. Williams, 1977, "Estimating betas from nonsynchronous data", Journal of Financial Economics, 5, 309-327.

Schwert, G., 1990, "Indices of United States stock prices, 1802-1987", Journal of Business, 63, 399-426.

W. Sharpe, G. Alexander, and J. Bailey, 1995, Investments, Prentice-Hall, Inc., Englewood Cliffs, 
New Jersey.

Sweeney, R., 1986, "Beating the foreign exchange market", Journal of Finance, 41, 163-182.

H. Stoll and R. Whaley, 1983, "Transactions costs and the small firm effect", Journal of Financial Economics, 12, 57-79. 